\title{
Aplicação do MASP na solução de problemas de reprocessamento de embalagens de água sanitária
}

\author{
Application of MASP in the solution of problems of reprocessing of sanitary water \\ containers
}

Natiany Gayão ${ }^{\mathbf{1 , 2}}$ orcid.org/0000-0001-7501-5766

Luciana Bazante 2,3 orcid.org/0000-0001-9115-896X

${ }^{1}$ Engenharia civil, Centro de Ciências e Tecnologia, Universidade Católica de Pernambuco, Recife, Brasil,
2 Pós-graduação em Gestão da Qualidade e Produtividade, Escola Politécnica de Pernambuco, Pernambuco, Brasil,
${ }^{3}$ Escola Politécnica de Pernambuco, Recife, Pernambuco, Brasil.
E-mail do autor principal: Natiany Gayão natianylemos@gmail.com

Resumo

Este trabalho demonstra a importância da aplicação do Método de Análise e Solução de Problemas e, consequentemente, das ferramentas da qualidade para a obtenção de bons resultados na eliminação de erros e implantação da melhoria contínua no processo de fabricação de embalagens para água sanitária. Tendo em vista o impacto que o contato com a água sanitária pode causar aos seus usuários, é importante oferecer embalagens confiáveis para o uso e armazenamento deste produto químico. A empresa tinha uma elevada taxa de reprocesso de garrafas, devido a problemas na produção das mesmas. A implantação do Método de Análise e Solução de Problemas, junto com a aplicação das ferramentas da qualidade que são parte deste método, tornou possível identificar e solucionar os problemas, estabilizando a taxa de reprocesso das embalagens, e atingindo a sistemática da melhoria contínua nos processos e produtos oferecidos para o consumidor final.

Palavras-Chave: MASP; Ferramentas da Qualidade; Embalagem; Produtos de limpeza.

\begin{abstract}
This work demonstrates the importance of applying the Analysis and Problem Solving Method and, consequently, of the quality tools to obtain good results to eliminate errors and implement continuous improvement in the manufacturing process of bottles for cleaning bleach. Considering the impact that contact with bleach can cause to its users, it is important to provide reliable packaging for the use and storage of this chemical product. The company had a high rate of reprocessing of bottles, due to problems in its production. The implementation of Analysis and Problem Solving Method, along with the application of the quality tools which are part of this method, made the company able to identify and solve the problems, stabilizing the reprocessing rate of the packaging, reaching the continuous improvement of the processes and products offered to the final consumer.
\end{abstract}

Key-words: MASP; Quality tools; Packing; Cleaning products. 


\section{Introdução}

A partir dos anos 30 e até o final dos anos 80 , os avanços da industrialização brasileira marcam os esforços da sociedade no caminho da melhoria, mas nem sempre estiveram associados à busca de níveis de produtividade de ponta [1].

A partir do início dos anos 90 , foi observado que um novo padrão de desenvolvimento estava se firmando na sociedade brasileira. No contexto desse novo padrão, foram altos os aumentos da produtividade na indústria brasileira, em quase todos os seus segmentos [1].

Com o passar dos anos, o mercado passou a ser muito mais competitivo e os consumidores se tornaram mais informados e exigentes.

Considerando este contexto, as empresas adotaram estratégias buscando as soluções em métodos organizacionais e gerenciais, por vezes com o auxílio de ferramentas que possibilitem sua adaptação e sobrevivência num ambiente complexo e competitivo gerando melhorias contínuas, além de possibilitar o sustento por suas atividades.

Diante deste cenário, o Controle de Qualidade Total (TQC) foi uma das estratégias encontradas pelas empresas com base na melhoria contínua. Unindo todos os setores da empresa para identificar os problemas e controlar a qualidade de seus produtos e processos [1].

O Método de Análise e Solução de Problemas (MASP) é uma sistemática muito utilizada dentro das empresas, permitindo manter e controlar a qualidade dos produtos, processos, ou serviços, através da abordagem de situações que exijam a tomada de decisões frente a uma situação insatisfatória, desvio do padrão de desempenho esperado, ou um objetivo pré-estabelecido. Essas situações são trabalhadas através da aplicação das ferramentas da qualidade de forma sequencial e padronizada, obedecendo um ciclo de definição, análise, melhoria, padronização e controle do problema [2].

Este estudo tem por objetivo aplicar o MASP para identificar adequadamente $\mathrm{o}$ problema percebido em uma indústria de produtos de limpeza. O estudo foi realizado no reprocesso de garrafas de água sanitária, que apresentava valores maiores que o desejado pela empresa.

As embalagens utilizadas para armazenamento de água sanitária costumam ser produzidas com o uso de polietileno, um material plástico que pode ser reaproveitado. Em caso de fabricação incorreta das garrafas, elas são reprocessadas (moídas e devolvidas ao processo), porém o material não apresenta o mesmo desempenho quando comparado ao material virgem. O reprocesso das embalagens gera diversas perdas, como energia elétrica, hora/homem, redução da produtividade, entre outros fatores.

Em 2016, a taxa de reprocessamento das garrafas de água sanitária correspondia a 0,79\%, estando $0,14 \%$ superior à desejada pela empresa. Portanto, será utilizado o MASP para solucionar o problema de reprocessamento da empresa.

\section{Referencial Teórico}

\section{1 Água sanitária}

A água sanitária é um produto químico, resultante da mistura de água com hipoclorito de sódio. É um produto muito utilizado pela população, devido às suas várias aplicações e ação eficaz sobre as regiões aplicadas. O produto é destinado à limpeza, branqueamento e desinfecção de superfícies, eliminando germes e bactérias, evitando o aparecimento de doenças causadas pela falta de limpeza, tanto em residências quanto em hospitais [3].

A água sanitária também é muito utilizada para desinfecção de água para consumo humano, devido ao seu baixo custo, fácil aplicação, ação antibacteriana e tempo curto para exercer sua atividade antimicrobiana [4].

Por se tratar de um produto químico muito utilizado pela população, as regras de fabricação devem ser seguidas rigorosamente assim como os controles de qualidade, garantindo a eficiência e confiabilidade para os consumidores sem oferecer riscos a sua segurança. Portanto, para segurança das embalagens, é de suma importância para a todos, a indústria e o consumidor final.

Segundo a Associação Brasileira de Normas Técnicas (ABNT, NBR 13390), o produto deve seguir as especificações contidas na norma de Embalagens plásticas para água sanitária e alvejantes à base de cloro [5].

O material da embalagem primária deve ser opaco, de plástico rígido e de difícil ruptura, de composição e porosidade adequadas de modo a não 
permitir que ocorram reações químicas entre 0 produto e a embalagem, mudança de cor do produto, transferência de odores ou migração de substâncias para o produto, bem como migração do produto para o meio externo [6].

\subsection{Embalagem da água sanitária}

A embalagem para água sanitária deve ser bem vedada, com fechamento que impeça vazamentos ou eventuais acidentes e de tal maneira que possa voltar a ser fechada várias vezes durante o uso, sem o risco de contato com o produto, dificultando a abertura acidental ou casual durante o período de utilização do produto [6].

A maioria das embalagens para este produto encontrada no mercado brasileiro é de polietileno, que pode ser produzido em diferentes densidades e formas. O tipo de polietileno mais usado na produção das garrafas de água sanitária é PEAD - Polietileno de Alta Densidade, sendo algumas de suas características:

- É um termoplástico relativamente barato;

- Alta resistência à tensão;

- Alta resistência à compressão;

- Baixa densidade em comparação com metais e outros materiais;

- Impermeabilidade;

- Não transmitem cor ou sabor ao produto;

- É atóxico

- Etc.

As embalagens costumam ser feitas em moldagem por sopro, que é uma combinação dos processos de termoformagem e extrusão. O plástico granulado é destinado ao funil da máquina, sendo transportado por uma rosca através de um cilindro, para então ser fundido pelo calor de resistências elétricas e do próprio atrito interno. Ao passar pela matriz da extrusora, o material toma a forma de uma mangueira líquida, comumente chamada de parison. Em seguida, o molde se fecha sobre essa mangueira, cortando com uma faca o parison e, depois, um bico de ar sopra o molde, formando a garrafa. Rapidamente o molde se resfria e expulsa as garrafas.

É importante garantir a qualidade das garrafas fabricadas e diminuir o índice de reprocesso, não apenas devido à perda financeira que pode gerar para a organização, mas por se tratar de um produto químico, a água sanitária precisa de embalagens confiáveis para serem levadas ao mercado.

\subsection{Controle da Qualidade Total - TQC}

Um produto ou serviço de qualidade é aquele que atende perfeitamente, de forma confiável, acessível e segura, no tempo certo, às necessidades do cliente [7].

A evolução histórica do controle de qualidade inicia-se desde quando o homem primitivo era tanto o produtor como o consumidor. Com posterior desenvolvimento, o homem que produzia passou a vender seus bens a terceiros, porém com a revolução industrial, surgiu a necessidade do intermediário, ou comerciante. Devido à complexidade da indústria e o tamanho cada vez maior das empresas, passou a se requerer um tipo diferente de organização: um homem só já não era capaz de controlar a qualidade, surgindo então a necessidade de diversificar as funções e, consequentemente, a organização. Desenvolveu-se a inspeção com a ajuda da estatística. Mas, na indústria moderna, é necessário algo mais, a atividade do controle da qualidade total (TQC) [8].

Portanto, a qualidade mudou com o tempo para se adaptar e satisfazer as novas exigências do consumidor moderno, no que diz respeito à qualidade do serviço/produto.

A melhoria contínua é uma abordagem de otimização, também chamada de Kaizen. Trata-se de um processo de aprimoramento contínuo que busca otimização pela inovação dos processos produtivos, dos métodos, dos produtos, das regras e dos procedimentos. Ele visa eliminar todos os problemas de uma organização por meio da identificação de potenciais melhorias, o que se torna possível pela participação de todos os colaboradores nas análises e também na resolução de possíveis problemas [9].

Uma forma de melhorar os níveis de qualidade dos produtos, dos serviços e dos processos é o controle da qualidade total ou TQC, que é um sistema administrativo aperfeiçoado no Japão, a partir de ideias americanas introduzidas logo após a Segunda Guerra Mundial, baseado na participação de todos os setores da empresa e todos os empregados no estudo e na condução do controle da qualidade [7].

http://dx.doi.org/10.25286/repa.v4i1.921 
É importante evidenciar a diferença entre os conceitos do controle da qualidade e do controle da qualidade total. O controle da qualidade, à grosso modo, é basicamente o processo de garantia dos requisitos do produto. Já o TQC, é um sistema que tem foco na melhora da qualidade em todos os processos da empresa, para que eles trabalhem juntos no mesmo objetivo.

\subsection{0 ciclo PDCA}

O PDCA é um método de gerenciamento de processos ou de sistemas. É o caminho para se atingirem as metas atribuídas aos produtos dos sistemas empresariais [7].

Essa metodologia tem como função básica o auxílio no diagnóstico, análise e prognóstico de problemas organizacionais, sendo extremamente útil para a solução de problemas. Poucos instrumentos se mostram tão efetivos para a busca do aperfeiçoamento quanto este método de melhoria contínua, tendo em vista que ele conduz a ações sistemáticas que agilizam a obtenção de melhores resultados com a finalidade de garantir a sobrevivência e o crescimento das organizações [10].

O ciclo PDCA é projetado para ser usado como um modelo dinâmico em que a conclusão de um ciclo irá fluir no começo do próximo ciclo, e assim sucessivamente. Além disso, o mesmo afirma que o processo sempre pode ter uma nova análise, o que implica em novo processo de mudança [11]. A Figura 1 mostra o ciclo PDCA.

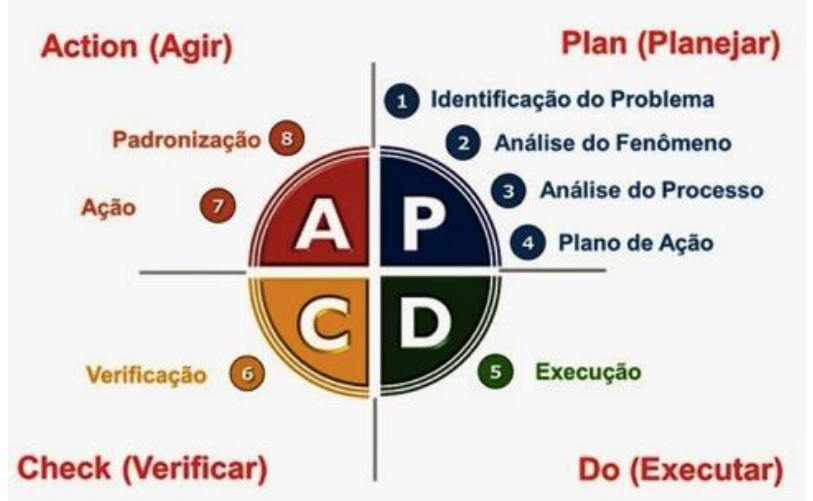

Figura 1: Ciclo PDCA e suas etapas Fonte: Peters (1998).
O Ciclo PDCA está dividido em quatro fases bem definidas e distintas, e que de acordo com Andrade [11], pode ser descrito da seguinte forma:

Plan (Planejar): estabelecer os objetivos e os processos necessários para fornecer resultados de acordo com os requisitos do cliente e políticas da organização. Esta etapa abrange: a identificação do problema, a definição de uma meta, a análise do fenômeno (utilizando diagramas estatísticos), a análise do processo (utilizando do diagrama de causa e efeito) e a elaboração do plano de ação;

Do (Fazer): implementar os processos, ou seja, execução das ações estabelecidas no plano de ação definidas na fase anterior, sendo realizadas no cronograma determinado, tendo todas as ações registradas e supervisionas;

Check (Checar): nesta fase deve-se executar a verificação da eficácia das ações tomadas na fase anterior. Utilizando para a mesma a comparação dos resultados (planejados e executados), listagem dos efeitos secundários (oriundos das ações executadas), verificação da continuidade ou não do problema (eficácia das ações tomadas);

Action (Agir): esta fase é responsável pela padronização dos procedimentos implantados na fase "Do", ou seja, sendo o resultado satisfatório, devemse padronizar essas ações, transformando-as em procedimentos padrão. Para realizar essa padronização é feita a elaboração ou alteração do padrão, comunicação, treinamento e acompanhamento da utilização do novo padrão. A conclusão do projeto também ocorre nessa fase, sendo que poderão ser estipuladas novas metas futuras para que o processo de melhoria continua possa ser desencadeado.

O ciclo do PDCA pode ser considerado como base para a qualidade, através do princípio de melhoria contínua e das diferentes formas que ele pode ser utilizado com objetivo de melhorar e/ou manter o gerenciamento.

Para auxiliar a aplicação do ciclo PDCA, existem as ferramentas da qualidade, descritas a seguir, que podem ser facilmente interpretadas e utilizadas em diversas fases, de maneira a atingir os resultados esperados. 


\subsection{Ferramentas da qualidade}

As ferramentas da qualidade são recursos utilizados para o levantamento e tratamento de fatos e dados, de forma a evitar o mal dimensionamento, não concluir por intuição e promover a análise de todos os ângulos da questão.

Algumas ferramentas são mais apropriadas para identificação de problemas, outras servem para análise de problemas e existem aquelas que podem ser utilizadas tanto na fase de identificação de problemas como na análise de problemas [13]. Abaixo, seguem as sete ferramentas básicas da qualidade:

- Fluxograma: é uma representação gráfica de um processo ou atividade. Utilizando símbolos padronizados, permite a análise para detecção de falhas e de oportunidades de melhorias [14].

- Diagrama de causa e efeito: também conhecido como "espinha de peixe" ou diagrama de Ishikawa, é uma ferramenta que ajuda a identificar as possíveis causas dos problemas [13].

- Folha de verificação: é uma ferramenta usada para quantificar a frequência em que certos eventos ocorrem. Sua função é garantir que o ganho obtido pela aplicação das outras ferramentas estatísticas não seja perdido ou esquecido depois que os problemas forrem solucionados [15].

- Análise de Pareto: seu objetivo é classificar em ordem decrescente os problemas que produzem os maiores efeitos e atacar estes problemas inicialmente. Desta forma, a solução é direcionada exatamente para coisas mais importantes em primeiro lugar [15].

- Histograma: é um gráfico de barras que mostra a distribuição de dados por categorias. Seu objetivo é apresentação dos dados obtidos em uma observação, de forma a simplificar a comparação de suas frequências de ocorrência [15].

- Diagrama de Dispersão: É um método rápido, simples e prático para verificar se existe dispersão ou relacionamento ou correlação entre duas variáveis [16].

- Cartas de Controle: é um gráfico de controle que serve para acompanhar a variabilidade de um processo, identificando suas causas comuns (variação normal do processo) e causas especiais (problemas decorrentes de falha operacional) [15].
Algumas ferramentas auxiliares da qualidade:

- Brainstorming: em português, quer dizer "tempestade cerebral". O brainstorming é uma técnica para coletar ideias, em grupo, que envolve a contribuição espontânea de todos os participantes. São atingidas soluções criativas e inovadoras para os problemas, rompendo com paradigmas estabelecidos. O clima de envolvimento e motivação gerado pelo brainstorming assegura melhor qualidade nas decisões tomadas pelo grupo, maior comprometimento com a ação e um sentimento de responsabilidade compartilhado por todos [17].

- 5W2H (plano de ação): É uma ferramenta utilizada para planejar a implementação de uma solução, sendo elaborado em resposta às questões a seguir [17]:

O que (What): Qual ação vai ser desenvolvida?

Quando (When): Quando a ação será realizada?

Por que (Why): Por que foi definida esta solução (resultado esperado)?

Onde (Where): Onde a ação será desenvolvida (abrangência)?

Como (How): Como a ação vai ser implementada (passos da ação)?

Quem (Who): Quem será o responsável pela sua implantação?

Quanto (How much): Quanto será gasto?

Com as respostas dos questionamentos, montase um quadro para melhor visualização e acompanhamento da solução do problema.

- Ferramentas para coleta de dados (lista): é a utilização de técnicas através das quais serão coletadas informações para identificar o problema ou justificar a sua solução, sendo as listas de verificações e fichas de análises mais comuns [18].

Embora a finalidade da lista de verificação seja o acompanhamento de dados e não a sua análise, ela normalmente indica qual é o problema e permite observar, entre outros, os seguintes aspectos: número de vezes em que algo acontece; tempo necessário para que algo seja feito; custo de uma determinada operação ao longo de certo período de tempo; impacto de uma ação ao longo de um dado período de tempo [17]. Na maioria das vezes, criam-se gráficos para facilitar o entendimento e as observações a serem feitas, a partir dos dados coletados.

http: / / dx.doi.org/10.25286/repa.v4i1.921 


\subsection{Metodologia de Análise e Solução de Problemas - MASP}

A Metodologia de Análise e Solução de Problemas (MASP) é uma forma estruturada de analisar e solucionar problemas da rotina diária das organizações, também conhecida como QC Story, oriunda do movimento da Qualidade Total no Japão [18].

De acordo com Hitoshi Kume [20]: "A solução de um problema é melhorar o resultado deficiente para um nível razoável. As causas do problema são investigadas sob o ponto de vista dos fatos, e a relação causa e efeito é analisada com detalhe. Decisões sem fundamento, baseadas em imaginação ou cogitações teóricas, são estritamente evitadas, visto que tentativas de resolver problemas por tais decisões conduzem a direções erradas, incorrendo em falha ou atraso na melhoria. Para evitar a repetição dos fatores causais, são planejadas e implantadas contramedidas para o problema. Este relato é uma espécie de história ou enredo das atividades do controle da qualidade e, por causa disso, as pessoas chamam-no de QC Story."

O MASP e o PDCA estão diretamente relacionados, conforme pode ser visualizado no Quadro 1.

Quadro 1: MASP e PDCA [19]

\begin{tabular}{|c|c|c|c|}
\hline PDCA & FLUXOGRAMA & FASE DO MASP & OBJetiVO \\
\hline \multirow{4}{*}{$\mathbf{P}$} & & Identificaçäo do problema & Definir o problema e verificar sua importância. \\
\hline & & Observaçăo & Investigar as caracteristicas do problema. \\
\hline & & Análise & Descobrir as causas fundamentais. \\
\hline & & Plano de Açăo & Conceber um plano para as causas fundamentais. \\
\hline D & & Execuçẵo & Aplicar o plano para bloquear as caussas. \\
\hline \multirow{2}{*}{ C } & & Verificaçăo & Verificar se o bloqueio foi efetivo. \\
\hline & & \multicolumn{2}{|l|}{ Bloqueio foi efetivo? } \\
\hline \multirow{2}{*}{ A } & & Padronização & Prevenir contra o reaparecimento do problema. \\
\hline & & Conclustio & Recapitular o processso de solução de problemas para trabalhos futuros. \\
\hline
\end{tabular}

Fonte: ENAP (2015).

É possível notar no Quadro 1 que cada fase do MASP está relacionada a uma das etapas do ciclo PDCA e que a ligação entre elas é baseada no que cada etapa representa dentro da lógica da melhoria contínua [21].
Sendo assim, o MASP é composto oito fases que busca a manutenção ou melhoria dos padrões através de ferramentas variadas, organizando e transformando os dados e fatos em informações. Ele permite a solução dos problemas de maneira sistemática e efetiva, possibilitando que as sejam capacitadas para resolver os problemas de sua responsabilidade. O Quadro 2, detalha as principais ferramentas que podem ser utilizadas para cada fase.

Quadro 2: Principais ferramentas utilizadas no MASP

\begin{tabular}{|l|l|l|l|}
\hline \multicolumn{1}{|c|}{ Fase do MASP } & \multicolumn{1}{|c|}{ Ferramentas } \\
\hline Eatos e dados existentes & \multicolumn{1}{|c|}{ Fatos existentes } \\
\hline Andos históricos \\
Análise de Pareto \\
Fluxograma
\end{tabular}

Fonte: ENAP (2015).

Segundo Campos [22], o MASP é composto por 8 fases, que seguem as premissas do ciclo PDCA. Estas fases são apresentados a seguir:

- Primeira fase: Identificação do problema

Para identificar um problema, todo o processo deverá ser estudado através de fatos e dados existentes com o auxílio de algumas ferramentas da qualidade.

Deve-se realizar a coleta dos dados históricos para identificar os possíveis pontos de problema, reconhecer sua importância e suas características iniciais (como, quando, e com qual frequência o(s) problema(s) ocorre $(\mathrm{m})$ ).

É importante expressar em termos concretos as perdas atuais e ganhos viáveis e comparar o que está perdendo e o que se pode ganhar. Para isto, deve-se identificar e quantificar o que está se perdendo no custo da qualidade atualmente, projetando uma tendência para estabelecer os possíveis ganhos viáveis. 
$\mathrm{Na}$ fase de priorização e definição do problema, caso tenha sido identificado mais de um ponto problemático, o próximo passo é a escolha do principal problema a ser solucionado.

Por fim, é necessário nomear responsáveis para encarregar-se oficialmente das tarefas e das metas fixadas.

As ferramentas mais adotadas nesta etapa são: dados históricos, diagrama de Pareto, fluxograma e brainstorming.

- Segunda fase: Observação

Esta fase consiste na investigação das características específicas do problema, a partir de uma ampla gama de diferentes pontos de vista.

$\mathrm{Na}$ caracterização do problema, deve ser descoberta a variação dos resultados, detalhando o problema e estratificando-o por características, como: tempo, local, tipo, sintoma e indivíduo.

É necessário ir ao próprio local do problema e coletar informações necessárias que não podem ser registradas na forma de dados (exemplo: temperatura, comportamentos, luminosidade).

Por fim, deve ser elaborado um cronograma e orçamento estimado para a melhoria.

- Terceira fase: Análise

Nesta fase, deve ser feita a descoberta de quais são as principais causas do problema.

Sugere-se a formação do grupo de trabalho para levantar as possíveis causas do problema, definindo as causas influentes. Em seguida, selecionam-se as causas principais e são revisadas as causas que foram definidas anteriormente, para descartar qualquer elemento que não seja claramente relevante.

São delineados novos planos para apurar o efeito que as causas consideradas como principais tem sobre o problema, através da obtenção de novos dados ou pela execução de experimentos. É promovida a integração de todas as informações investigadas e decididas quais são as causas principais. Se possível, reproduzir intencionalmente o problema.

Deve ser verificado se houve confirmação de alguma causa provável. Através dos resultados das experiências, é possível confirmar ou não a relação entre causa e problema. Se houver confirmação, segue para a próxima etapa do teste de consistência.
Caso contrário, deverá ser feita uma outra escolha das causas mais prováveis.

A consistência da causa fundamental deve ser testada, verificando se o bloqueio é tecnicamente possível ou não e se geraria efeitos indesejáveis. Caso não seja possível, deverá voltar para o início da análise do problema e escolha das causas.

- Quarta fase: Plano de ação

É o último passo da fase de planejamento, onde deve ser elaborado um plano para bloquear o problema, eliminando as causas fundamentais.

Serão planejadas ações para contenção e bloqueio do problema, examinando as vantagens e desvantagens de cada uma e selecionando aquela com as quais o pessoal envolvido esteja de acordo, escrevendo o plano de ação de acordo com as perguntas do $5 \mathrm{~W} 2 \mathrm{H}$ (ou as possíveis variações na quantidade de perguntas que uma empresa venha a adotar).

\section{- Quinta fase: Execução}

Nesta fase, ocorre a transformação do plano de ação em ação em prática, agindo para bloquear as causas do problema.

Todos os envolvidos devem ser treinados, conhecendo o plano de ação e as ações que lhes cabem.

Por fim, é possível executar as ações, seguindo o plano de ação e o cronograma estabelecido anteriormente e verificando se as ações estão sendo efetuadas.

- Sexta fase: Verificação

Verificar se o bloqueio foi efetivo e certificar-se que o problema não ocorrerá novamente.

Comparar os resultados indesejáveis relativos ao tema, obtidos antes e depois da execução das ações, em um mesmo formato (tabelas, gráficos e/ou diagramas).

Em seguida, listar os efeitos secundários, visto que toda alteração do sistema pode provocar efeitos secundários positivos ou negativos.

Verificar a continuidade do problema, com base nos dados coletados no mapa anterior, checando se o bloqueio foi efetivo. Se as alterações tomadas não funcionaram, voltar a segunda fase.

- Sétima fase: Padronização

http://dx.doi.org/10.25286/repa.v4i1.921 
Esta fase servirá para eliminar definitivamente o reaparecimento do problema, quando a empresa irá elaborar um padrão que não exista sobre o tema abordado ou alterar um padrão existente, além de comunicar e treinar as pessoas envolvidas. Deve ocorrer o acompanhamento da utilização do padrão.

\section{- Oitava fase: Conclusão}

Aqui, será feita uma avaliação da resolução do problema e planejamento do trabalho futuro.

Serão relacionados os problemas remanescentes e o que não foi realizado, bem como os resultados acima do esperado. Em seguida, planejar o que deve ser feito para resolver os problemas remanescentes e reavaliar os itens pendentes.

Refletir sobre as coisas que transcorreram bem ou mal durante as atividades, analisando as etapas executadas e refletindo sobre as atividades realizadas.

\section{Metodologia}

O presente trabalho apresenta a aplicação do MASP para solucionar e eliminar possíveis recorrências de problemas de reprocesso na produção da embalagens de água sanitária encontrados numa indústria de produtos de limpeza, localizada na Região Metropolitana de Recife.

O estudo de caso contém as oito fases do MASP, aplicadas para a solução do reprocessamento de garrafas de água sanitária. Desde a identificação e escolha do problema, até a conclusão de sua solução, foram usadas algumas ferramentas da qualidade para garantir melhores resultados no processo de produção que apresentou falha.

\section{Resultados e Discussão}

\subsection{Identificação do problema}

No setor de produção, observou-se um número expressivo no que se diz respeito ao reprocesso das garrafas plásticas. Portanto, os dados foram coletados para escolha do problema a ser solucionado.

A linha de produção das garrafas para o armazenamento de água sanitária é bastante variada, apresentando quatro marcas diferentes ( $A$, 53
B, C e D), cada marca possui quatro embalagens com volumes distintos (um litro, dois litros, cinco litros e quinhentos mililitros).

$\mathrm{Na}$ aplicação das etapas do MASP, inicialmente, foram identificados os produtos que apresentaram 0 maior número de não conformidades (vazamentos e má formação). Após o levantamento do histórico do problema, foi desenvolvido um gráfico sequencial para melhor análise anual do problema. O Gráfico 1 demonstra o alto índice de reprocesso das garrafas. A meta anual de reprocesso estabelecida pela empresa era de $0,65 \%$, porém a média de reprocessos no ano de 2016 correspondia a 0,79\%, estando $0,14 \%$ acima da meta estimada. Portanto, a empresa buscou reduzir a quantidade de reprocesso para atingir e estabilizar o índice de $0,65 \%$ de reprocessamento anual.

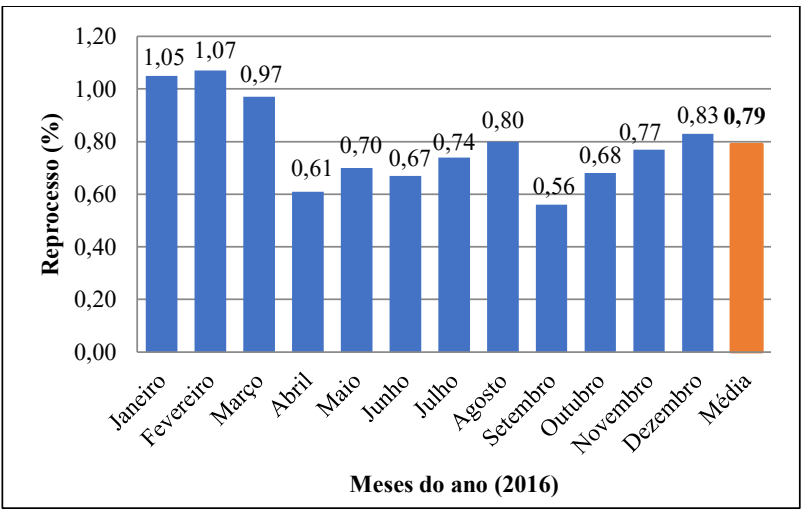

Gráfico 1: Reprocesso anual das garrafas 2016

Fonte: Autora (2017).

Diante da grande variedade de garrafas produzidas, foram estratificados os dados para poder localizar o tipo de garrafa que apresenta maior incidência de reprocesso. No Gráfico 2, é possível identificar que 0 aspecto mais relevante a ser atacado são as garrafas de um litro, responsáveis por $55 \%$ do reprocesso anual das garrafas.

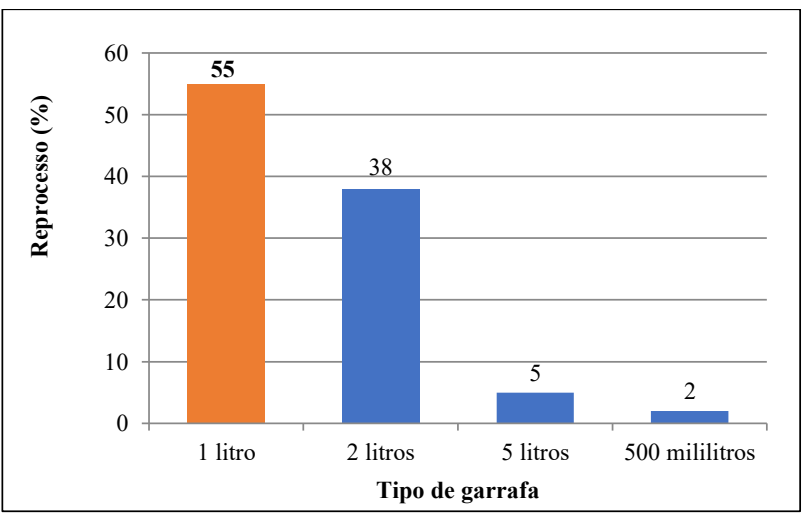

Gráfico 2: Reprocesso anual por tipo de garrafa 2016 
Fonte: Autora (2017).

Para melhor análise do problema, foram estratificados os dados em função do custo médio mensal de reprocessos por tipo de garrafa. Conforme - Gráfico 3, o custo mensal para as garrafas de um litro corresponde a praticamente $60 \%$ do valor total gasto com reprocesso. O custo médio mensal de reprocesso das garrafas de um litro era de $\mathrm{R} \$ 9.026,00$ com reprocesso a $0,79 \%$, firmando a priorização para solução dos problemas das garrafas de um litro por apresentam maior incidência nos resultados.

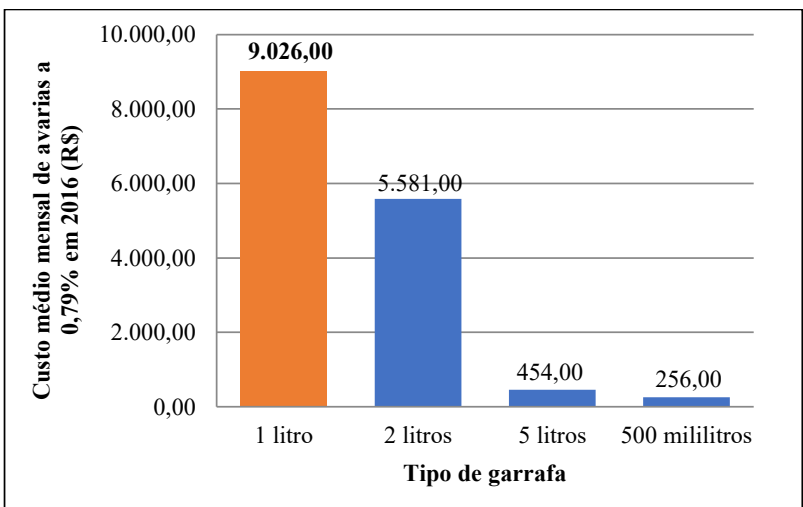

Gráfico 3: Custo médio mensal de reprocesso a $0,76 \%$ de janeiro a dezembro de 2016

Fonte: Autora (2017).

Considerando o foco no reprocesso das garrafas de um litro, levantou-se o faturamento médio mensal sem avarias e foram realizados comparativos do faturamento com avarias a $0,79 \%$ e a $0,65 \%$, conforme mostra o Gráfico 4. Constata-se que o faturamento médio mensal sem os gastos com avarias corresponde a $\mathrm{R} \$ 315.000,00$, porém com a atual taxa de reprocesso, $0,79 \%$, o faturamento cai para R\$305.974,00/ano. Estimando o faturamento com o reprocesso a $0,65 \%$, tem-se o aumento do faturamento para $\mathrm{R} \$ 307.573,54 / \mathrm{ano}$, fazendo uma projeção dos ganhos viáveis. Ou seja, ao diminuir a quantidade de reprocessos, o faturamento aumenta $\mathrm{e}$, consequentemente, o custo mensal é reduzido.

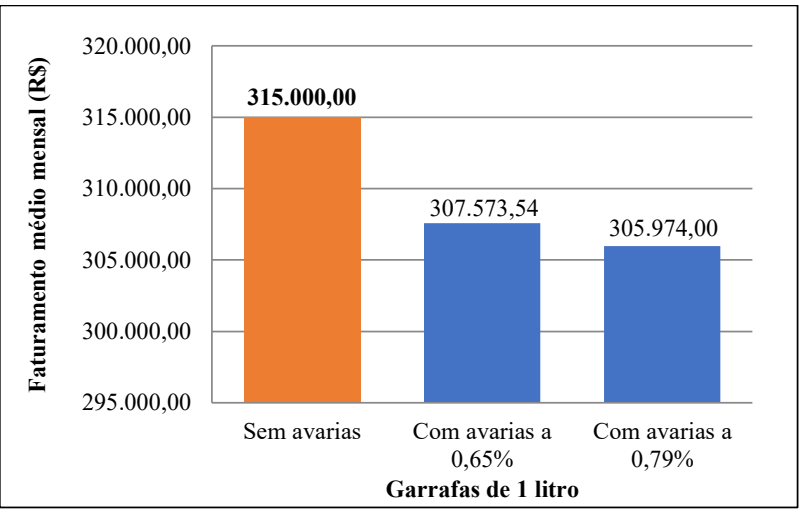

Gráfico 4: Comparativo do faturamento médio mensal das garrafas de 1 litro

Fonte: Autora (2017).

Identificado que as garrafas de um litro apresentam maior registro de avarias, foram estratificados os dados para identificar a marca de água sanitária que apresentava maior incidência de reprocesso para realizar a intervenção do problema.

Inicialmente, foi realizada a estratificação dos dados de reprocesso anual das garrafas de um litro. O Gráfico 5 apresenta a quantidade de caixas que foram reprocessadas por cada marca no período. As garrafas da marca " $A$ " de um litro, apresentaram o maior número de caixas reprocessadas no total de quatro mil duzentos e noventa e um. Em seguida a marca " $B$ " com um mil quatrocentos e vinte e quatro caixas reprocessadas. Comparando as duas marcas mais defeituosas, as garrafas da marca " $A$ " correspondem a um pouco mais que três vezes a quantidade da segunda marca de garrafa mais reprocessada.

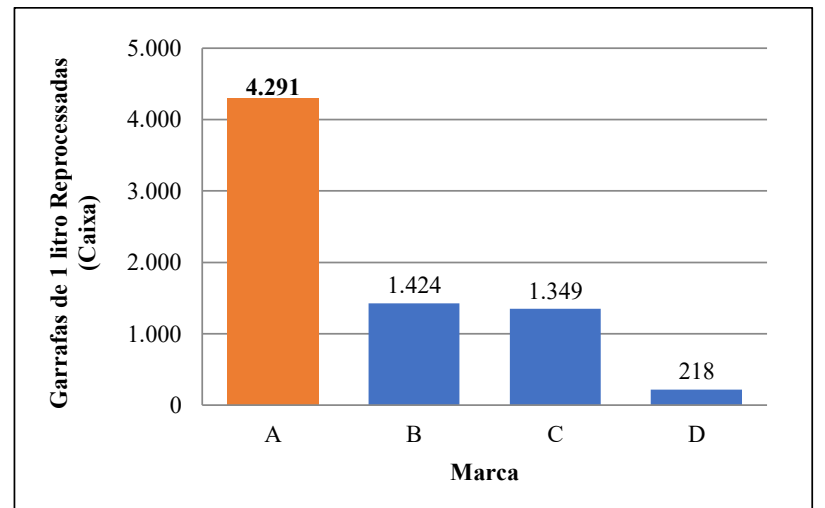

Gráfico 5: Caixas reprocessadas de garrafas de 1 litro por marca

Fonte: Autora (2017).

Continuando a estratificação dos dados, obteve-se o Gráfico 6, que indica a porcentagem dos produtos de um litro que foram reprocessados em relação a 
produção total de cada marca. Para a marca "A" dos $100 \%$ das garrafas produzidas, $62 \%$ foram reprocessadas. Para a marca "B" $29 \%$ da produção foi reprocessada. E para as marcas "C" e "D", 34\% e $25 \%$, respectivamente. Novamente, as garrafas da marca " $A$ " seguem em destaque na quantidade de reprocessos.

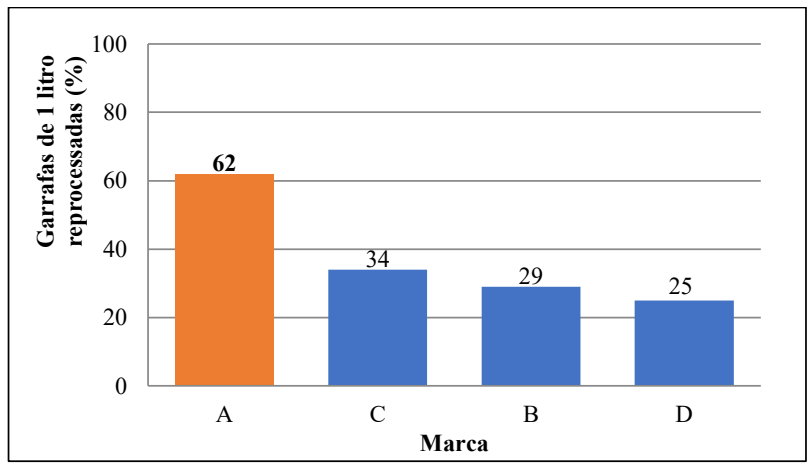

Gráfico 6: Garrafas de 1 litro reprocessadas (\%) Fonte: Autora (2017).

Sendo assim, com as estratificações realizadas até então, foram identificados a marca e o tipo de garrafa que apresentaram forte impacto na quantidade de reprocessos. Foram levantados e quantificados os principais defeitos para ocorrência dos reprocessos das garrafas da marca " $A$ " de um litro, conforme mostra o Gráfico 7, o defeito em destaque ficou para a emenda de fundo, responsável por $23,4 \%$ dos reprocessos.

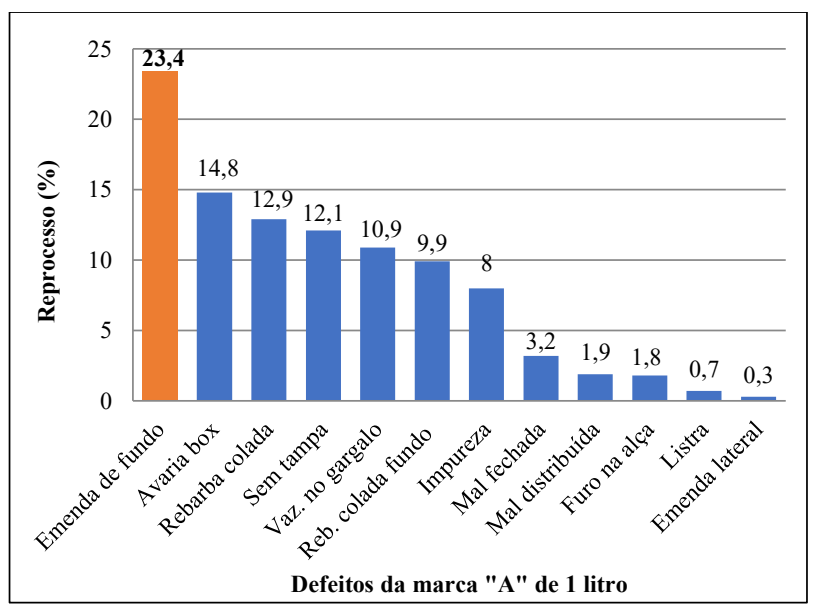

Gráfico 7: Reprocesso por defeitos da marca "A" de 1 litro Fonte: Autora (2017).

Sendo assim, define-se problema a ser atacado: o alto índice de reprocesso das garrafas da marca " $\mathrm{A}$ " de um litro devido ao defeito de emenda de fundo.
Para concluir a primeira fase do MASP, os responsáveis foram nomeados e suas tarefas definidas. Conforme o Quadro 3:

Quadro 3: Nomeação dos responsáveis e suas tarefas

\begin{tabular}{|l|l|}
\hline \multicolumn{1}{|c|}{ Responsável } & \multicolumn{1}{c|}{ Tarefas } \\
\hline Colaborador "A" & Efetuar as estratificações \\
\hline $\begin{array}{l}\text { Colaboradores } \\
\text { "B" e "C" }\end{array}$ & Fazer os estudos práticos no setor \\
\hline $\begin{array}{l}\text { Colaboradores } \\
\text { "D" e "E" }\end{array}$ & $\begin{array}{l}\text { Padronizar informações e manter o uso da } \\
\text { metodologia }\end{array}$ \\
\hline $\begin{array}{l}\text { Colaboradores } \\
\text { "F" e "G" }\end{array}$ & Validar informações in loco \\
\hline
\end{tabular}

Fonte: Autora (2017).

\subsection{Observação do problema}

$\mathrm{Na}$ fase de observação do problema, os dados foram coletados através da implantação de uma lista de verificação não formalizada, em branco, apenas para que o operador registrasse quais problemas aconteciam com mais frequência. Após 0 levantamento, a umidade no fundo do molde de sopro foi apontada como um problema que se repetia com bastante frequência, causando não conformidade nas garrafas.

Em seguida, foi realizada uma observação no local onde o problema acontecia para coletar informações necessárias ao seu entendimento e verificar as situações o influenciavam. Foi realizada a verificação da umidade do fundo do molde e evidenciado que a umidade poderia interferir na formação das garrafas, mas que em especial, foi percebido 0 descumprimento dos controles implantados (NBR13390) pelos operadores comprometia os resultados do processo.

Ao final desta fase criou-se um cronograma com as oito fases do MASP definidas dentro de um período de tempo de cumprimento, vide Apêndice 1 .

\subsection{Análise do problema}

Esta fase tem como objetivo descobrir as principais causas do problema. Primeiramente, foram descobertas as causas mais influentes e, em seguida, elas foram priorizadas pelo grupo e analisadas. 
Para definir as causas influentes, foi adotada a ferramenta Brainstorming. Formou-se um grupo com nove integrantes e foram listadas as possíveis causas do influentes problema, mostradas na Tabela 1.

Em seguida, foi realizada a ponderação das possíveis causas influentes para identificar as principais (as quatro primeiras na Tabela 1), considerando o maior percentual de ocorrência nas amostras estudadas.

Tabela 1: Possíveis causas influentes do problema

\begin{tabular}{|l|l|}
\hline \multicolumn{2}{|c|}{ Possíveis causas influentes } \\
\hline Molde prensando muito a rebarba & 15 \\
\hline Mangueira curta & 9 \\
\hline Fechamento de molde sem amortecimento & 8 \\
\hline Fundo do molde mal refrigerado & 5 \\
\hline Variação de temperatura nas zonas (Leitura incorreta) & 2 \\
\hline Conjunto rebarbador com desgaste & 2 \\
\hline Folga no movimento do rebarbador & 2 \\
\hline Saída de rebarba do molde irregular & 1 \\
\hline Temperatura da máquina/molde fora do padrão & 1 \\
\hline Molde com fiação deficiente & 1 \\
\hline Molde não fecha & 1 \\
\hline Reguladora de fluxo com desgaste prejudicando regulagem & 1 \\
\hline
\end{tabular}

Fonte: Autora (2017).

Para verificar a confirmação das quatro causas principais, foram realizados quatro testes para confirmar ou não a relação de causa e problema. 0 Quadro 4, detalha os testes das hipóteses, onde foi verificado que o molde estava prensando muito a rebarba e que as demais causas não influenciavam o problema.

Quadro 4: Resultado do teste das hipóteses

\begin{tabular}{|l|l|l|l|}
\hline \multicolumn{3}{|c|}{ Teste das hipóteses } \\
\hline Hipótese & Método & Resultado & Julgamento \\
\hline $\begin{array}{l}\text { Mangueira } \\
\text { curta }\end{array}$ & $\begin{array}{l}\text { Acompanhamento } \\
\text { da equipe no local } \\
\text { e acompanhamento } \\
\text { 24h usando lista de } \\
\text { verificação }\end{array}$ & $\begin{array}{l}\text { Não } \\
\text { evidenciado }\end{array}$ & $\begin{array}{l}\text { Não } \\
\text { influencia }\end{array}$ \\
\hline $\begin{array}{l}\text { Amortecimento } \\
\text { do fechamento } \\
\text { do molde }\end{array}$ & $\begin{array}{l}\text { Acompanhamento } \\
\text { da equipe no local } \\
\text { e acompanhamento } \\
24 h \text { usando lista de } \\
\text { verificação }\end{array}$ & $\begin{array}{l}\text { Não } \\
\text { evidenciado }\end{array}$ & $\begin{array}{l}\text { Não } \\
\text { influencia }\end{array}$ \\
\hline
\end{tabular}

\begin{tabular}{|l|l|l|l|}
\hline $\begin{array}{l}\text { Refrigeração } \\
\text { do fundo do } \\
\text { molde }\end{array}$ & $\begin{array}{l}\text { Acompanhamento } \\
\text { da equipe no local } \\
\text { e acompanhamento } \\
\text { 24h usando lista de } \\
\text { verificação }\end{array}$ & $\begin{array}{l}\text { Não } \\
\text { evidenciado }\end{array}$ & $\begin{array}{l}\text { Não } \\
\text { influencia }\end{array}$ \\
\hline $\begin{array}{l}\text { Molde } \\
\text { prensando } \\
\text { muito a rebarba }\end{array}$ & $\begin{array}{l}\text { Acompanhamento } \\
\text { da equipe no local } \\
\text { e acompanhamento usando lista de } \\
\text { verificação }\end{array}$ & $\begin{array}{l}\text { Evidenciado } \\
\text { visualmente }\end{array}$ & Influencia \\
\hline
\end{tabular}

Fonte: Autora (2017).

Em seguida, o teste de consistência, mostrado no Quadro 5, foi realizado para a causa que influenciava comprovadamente no problema. Neste teste, foi adotada a ferramenta dos cinco porquês para entender melhor $o$ que acontecia com aquele problema. Através do teste de consistência foi concluído que havia erro na confecção do molde, que causava rebarbas na garrafa.

Quadro 5: Teste de consistência

\begin{tabular}{|l|l|l|}
\hline \multicolumn{2}{|c|}{ Teste de consistência } \\
\hline \multicolumn{2}{|c|}{ Causa fundamental: Rebarba prensando muito } \\
\hline $\begin{array}{l}\text { Existe evidência técnica } \\
\text { de que é possível } \\
\text { bloquear? }\end{array}$ & $\begin{array}{l}\text { Sim, realizando alteração no } \\
\text { sistema de rebarbação do fundo } \\
\text { do molde. }\end{array}$ \\
\hline $\begin{array}{l}\text { O bloqueio geraria efeitos } \\
\text { indesejáveis? }\end{array}$ & $\begin{array}{l}\text { Não. } \\
\text { rebarba está } \\
\text { prensando } \\
\text { muito? }\end{array}$ & $\begin{array}{l}\text { Porque não há área suficiente } \\
\text { para acomodar as rebarbas do } \\
\text { produto. }\end{array}$ \\
\cline { 2 - 3 } Método & $\begin{array}{l}\text { 2. Por que não } \\
\text { há área } \\
\text { suficiente? }\end{array}$ & $\begin{array}{l}\text { Porque a área do fundo do } \\
\text { molde destinada para esta } \\
\text { acomodação está com } \\
\text { profundidade e saída da rebarba } \\
\text { insuficiente. }\end{array}$ \\
\cline { 2 - 3 } & $\begin{array}{l}\text { 3. Por que } \\
\text { está } \\
\text { insuficiente? }\end{array}$ & $\begin{array}{l}\text { Porque houve erro na confeç̧ão } \\
\text { da área de rebarbação do } \\
\text { molde. }\end{array}$ \\
\hline Conclusão: Erro na confecção da área de rebarbação do molde. \\
\hline
\end{tabular}

Fonte: Autora (2017).

\subsection{Plano de ação}

Nesta fase, criou-se um plano de ação, através de uma adaptação do $5 \mathrm{~W} 2 \mathrm{H}$ (excluindo as perguntas porque e quando) por ser o modelo adotado pela organização, relacionando as causas que foram http: / /dx.doi.org/10.25286/repa.v4i1.921 
encontradas e as ações para bloquear e eliminar os erros encontrados anteriormente. O Quadro 6 mostra o plano de ação final.

Quadro 6: Plano de ação

\begin{tabular}{|c|c|c|c|c|c|}
\hline \multicolumn{6}{|c|}{ PROBLEMA: Erro na confecção da área de rebarbação do molde } \\
\hline OQUE & COMO & QUEM & QUANDO & ONDE & STATUS \\
\hline \multirow{3}{*}{$\begin{array}{l}\text { Alterar área de } \\
\text { rebarbação dos moldes } \\
\text { da marca "A" de um litro } \\
\text { (Máquina } \mathrm{H} 155 \text { - 1) }\end{array}$} & $\begin{array}{l}\text { Enviando molde reserva da máquina } \\
\text { H155 - } 1 \text { para a ferramentaria (teste } \\
\text { piloto) }\end{array}$ & $\begin{array}{c}\text { Colaborador } \\
\text { "B" }\end{array}$ & $24 / 01 / 17$ & Ferramentaria & $\begin{array}{l}\text { OK, } \\
\text { Recebido } \\
\text { em } \\
30 / 01 / 17 \\
\end{array}$ \\
\hline & Substituindo pelo molde reserva & $\begin{array}{c}\text { Colaborador } \\
\text { "B" }\end{array}$ & $06 / 02 / 17$ & Setor Sopro AS & OK \\
\hline & Acompanhando resultado por 5 dias & $\begin{array}{c}\text { Colaborador } \\
\text { "A" }\end{array}$ & 06/02/17 & Setor Sopro AS & OK \\
\hline \multirow{3}{*}{$\begin{array}{l}\text { Alterar área de } \\
\text { rebarbação dos moldes } \\
\text { da marca "A" de um litro } \\
\text { (Máquina H155 - 2) }\end{array}$} & $\begin{array}{l}\text { Enviando molde reserva da máquina } \\
\text { H155 - } 2 \text { para a ferramentaria (teste } \\
\text { piloto) }\end{array}$ & $\begin{array}{c}\text { Colaborador } \\
\text { "B" }\end{array}$ & $07 / 02 / 17$ & Ferramentaria & $\begin{array}{l}\text { OK, } \\
\text { Recebido } \\
\text { em } \\
30 / 01 / 17 \\
\end{array}$ \\
\hline & Substituindo pelo molde reserva & $\begin{array}{c}\text { Colaborador } \\
\text { "B" }\end{array}$ & $17 / 02 / 17$ & Setor Sopro AS & OK \\
\hline & Acompanhando resultado por 5 dias & \begin{tabular}{|c|} 
Colaborador \\
"A"
\end{tabular} & $17 / 02 / 17$ & Setor Sopro AS & OK \\
\hline $\begin{array}{l}\text { Instalar medição de } \\
\text { umidade }\end{array}$ & Inst: & \begin{tabular}{|c|} 
Colaborador \\
"B"
\end{tabular} & $25 / 01 / 17$ & Setor Sopro AS & OK \\
\hline $\begin{array}{l}\text { Treinar equipe nos } \\
\text { controles }\end{array}$ & $\begin{array}{l}\text { Realizando treinamento da equipe } \\
\text { nos controles de qualidade }\end{array}$ & \begin{tabular}{|c|}
$\begin{array}{c}\text { Colaborador } \\
\text { "D" }\end{array}$ \\
\end{tabular} & $24 / 01 / 17$ & Auditório & OK \\
\hline
\end{tabular}

Fonte: Autora (2017).

\subsection{Execução}

O plano de ação foi aplicado, realizando a divulgação das ações para a equipe, certificando-se da sua concordância e entendimento de todos os envolvidos.

Também foi realizada a efetiva aplicação das ações para bloqueio das não conformidades e o acompanhamento das ações tomadas no local.

\subsection{Verificação}

Implementada a solução, o processo foi checado para verificar se o bloqueio foi efetivo. A forma de avaliação após a ação de bloqueio foi o teste e acompanhamento no local. Não foram evidenciados efeitos secundários após a execução da ação.

De acordo com o Gráfico 8, a quantidade de reprocessos diminuiu consideravelmente, quando comparadas as taxas de reprocesso do primeiro semestre do ano de intervenção (2017) com os valores do mesmo período do ano anterior (2016). A média semestral de reprocesso foi reduzida de $0,74 \%$ para $0,52 \%$, abaixo do valor médio desejado pela organização. Comprovando que as ações implantadas foram eficazes na redução do problema.

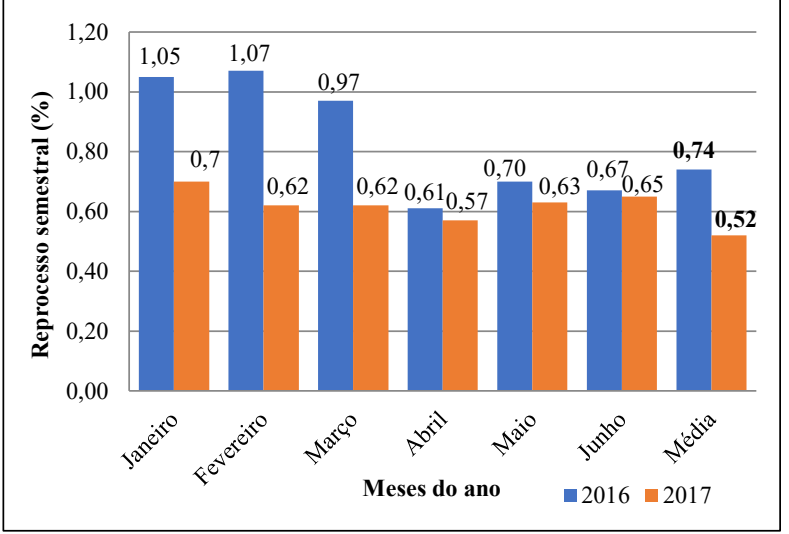

Gráfico 8: Reprocesso semestral das garrafas de 1 litro 2016 e 2017

Fonte: Autora (2017).

\subsection{Padronização}

A solução do problema foi a troca do molde da máquina, uma mudança de caráter ferramental, não havendo necessidade de alteração do padrão para esta ação. Ou seja, não houve necessidade de revisão do procedimento de controle, apenas retreinamento e conscientização dos executores.

Foi criado um procedimento para o acompanhamento da umidade, bem como realizado o treinamento do novo procedimento. Mesmo verificando que o a umidade não era uma causa fortemente influente, mas por ser muito presente em vários brainstormings, a equipe aproveitou para criar uma ação que combatesse o problema da umidade.

\subsection{Conclusão do MASP}

Observou-se que não havia possibilidade de retorno do alto índice de reprocesso após a implantação das ações, tendo sido apresentada constância nos resultados. Não foram evidenciados problemas remanescentes daqueles escolhidos para serem tratados.

A utilização do Método de Análise e Solução de Problemas foi eficaz na empresa de produção de água sanitária e suas embalagens.

O auxílio das ferramentas da qualidade foi relevante para a análise e solução de problemas.

Houve uma estabilização da taxa de reprocesso, sem ocasionar efeitos secundários no processo. 
Foram observados ganhos de diversos benefícios, tais como: aumento do faturamento, diminuição do desperdício, maior produtividade e qualidade de seus produtos.

É de grande importância a continuação trabalho para investigar as outras causas, visando eliminar totalmente o reprocesso de garrafas na empresa estudada.

\section{Conclusões}

Diante dos controles de qualidade, das normas a serem seguidas para produção de embalagens de água sanitária, bem como da busca pela melhoria contínua, é de fundamental importância solucionar os problemas que surgem durante sua produção de forma sistemática.

Foi observado um problema no reprocesso de água sanitária e a escolha do MASP para identificá-lo e solucioná-lo foi adequada, pois tentativas anteriores que não seguiram um método foram frustradas. Todas as oito fases foram seguidas $e$ através das ferramentas da qualidade apropriadas para cada fase, o objetivo foi atingido: a taxa de reprocesso da água sanitária estava acima do valor desejado, com aplicação do MASP, o reprocesso foi estabilizado com sucesso, sem ocasionar efeitos secundários no processo.

O fato gerou benefícios para a empresa, melhorando a imagem de seu produto com segurança na embalagem fornecida. Em termos de redução de custos, destaca-se a diminuição dos reprocessos, redução de tempo, mão-de-obra e gastos com embalagens, além da minimização do processo de retrabalho que além de originar custos extras para a empresa, gera transtornos durante 0 processo de produção.

Portanto, a metodologia mostrou-se eficaz na solução do problema de reprocesso das embalagens plásticas, baseada em fatos e dados e não por suposições. Ficou comprovado que, com a aplicação correta da metodologia, junto com a utilização de ferramentas da qualidade, foi possível identificar os problemas e as causas raízes, solucionando os problemas de forma eficaz e obtendo bons resultados.

\section{Referências}

[1] BRASIL, Ministério do Desenvolvimento, Indústria e Comércio Exterior; LODI, Instituto Euvaldo Lodi. $O$ futuro da indústria: oportunidades e desafios: a reflexão da universidade. Brasília: MDIC/STI: IEL NACIONAL, 2001.

[2] ARIOLI, E.E. Análise e solução de problemas: o método da qualidade total com dinâmica de grupo. 1 ed. Rio de Janeiro: Qualitymark, 1998.

[3] BRASIL. Instituto Nacional de Metrologia (INMETRO). Água Sanitária - Produto e Segurança da Embalagem. Disponível em: < http://www.inmetro.gov.br/consumidor/produtos /agua_sanitaria2.asp > acessado em agosto de 2017.

[4] TOMINAGA, Maria Y.; FIDIO, Antonio F. Exposição humana a trialometanos presentes em águas tratada. Revista de Saúde Pública. São Paulo. V.33, n.4, p.413-421, 1999.

[5] ASSOCIAÇÃO BRASILEIRA DE NORMAS TÉCNICAS. NBR 13390: Embalagens plásticas para água sanitária e alvejantes à base de cloro. Rio de Janeiro, 2006.

[6] BRASIL. Ministério da Saúde. Agência Nacional de Vigilância Sanitária. Legislação. Resolução RDC n. 55, de 10 de novembro de 2009. Dispõe sobre Regulamento Técnico para Produtos Saneantes Categorizados como Água Sanitária e Alvejantes à Base de Hipoclorito de Sódio ou Hipoclorito de Cálcio e dá outras providências. Disponível em: < https://www.diariodasleis.com.br/busca/exibelink .php?numlink=212943 > Acesso em: Agosto de 2017.

[7] CAMPOS, V.F. TQC: Controle da qualidade total (no estilo japonês). ( $5^{a}$ edição). Belo Horizonte: QFCO p.220, 1992.

[8] PALMER, C.F. Controle total de qualidade. São Paulo: Edgard Blucher LTDA, 1974.

[9] JUNIOR, E.L.C., Gestão em processos produtivos. Curitiba: Ibpex, 2008.

http: / / dx.doi.org/10.25286/repa.v4i1.921 
[10] QUINQUIOLO, J.M. Avaliação da eficácia de um sistema de gerenciamento para melhorias implantado na área de carroceria de uma linha de produção automotiva. 107f. Dissertação (Mestrado em Administração de Empresas) Universidade de Taubaté - UNITAU, Taubaté, 2002.

[11] ANDRADE, F.F.D. O método de melhorias PDCA. Dissertação (Mestrado em Engenharia Civil) - Escola Politécnica - EP: São Paulo, 2003.

[12] PETERS, T. O círculo da inovação. São Paulo: Harbra, 1998.

[13] RANGEL, A. Momento da qualidade. São Paulo: Atlas S.A., 1995.

[14] BRASSARD, M. Qualidade: Ferramentas para uma melhoria contínua. Rio de Janeiro: Qualitymark, 1996.

[15] PALADINI, E.P. Qualidade total na prática: implantação e avaliação de sistemas de qualidade total. São Paulo: Atlas, 1994.

[16] ABRANTES, J. Gestão da qualidade. Rio de Janeiro: Interciência, 2009.

[17] SEBRAE. Manual de Ferramentas da Qualidade. 2005. Disponível em: < http://www.dequi.eel.usp.br/ barcza/Ferrament asDaQualidadeSEBRAE.pdf > Acesso em Agosto de 2017.

[18] CORREA, P.F., Aplicação das ferramentas da qualidade na solução de problemas de contaminação em uma fábrica de chocolate. Recife, 2017.

[19] ENAP. Análise e melhoria de processos metodologia MASP. 2015. Disponível em: < http://repositorio.enap.gov.br/bitstream/1/2174/ $1 /$ MASP\%20-

\%20M\%C3\%B3dulo\%20\%281\%29.pdf > Acesso em Agosto de 2017.

[20] KUME, H. Métodos Estatísticos para Melhoria da Qualidade. 4aed. São Paulo: Gente, p. 245,1993 .
[21] BASTIANI, J. MASP (Método de Análise e Solução de problemas) - parte 2. Disponível em: $<\quad$ http://www.blogdaqualidade.com.br/maspmetodo-de-analise-e-solucao-de-problemasparte-2/ > . Acesso em: Agosto de 2017.

[22] CAMPOS, V.F. Gerenciamento pelas diretrizes (Hoshin Kanri). Belo Horizonte: Falconi, 2013 (5a edição) 270p. 


\section{Apêndice 1}

\section{Cronograma - Melhoria do reprocesso das garrafas de água sanitaria "A" de 1}

\begin{tabular}{|c|c|c|c|c|c|c|c|c|c|c|c|c|c|c|c|c|c|c|c|c|c|c|}
\hline & \multicolumn{4}{|c|}{ Novembro } & \multicolumn{4}{|c|}{ Dezembro } & \multicolumn{4}{|c|}{ Janeiro } & \multicolumn{4}{|c|}{ Fevereiro } & \multicolumn{4}{|c|}{ Março } \\
\hline & & & 1 & 2 & 3 & 4 & 5 & 6 & 7 & 8 & 9 & 10 & 11 & 12 & 13 & 14 & 15 & 16 & 17 & 18 & 19 & 20 \\
\hline \multicolumn{3}{|c|}{ Processo 1 - Identificação do problema } & & & & & & & & & & & & & & & & & & & & \\
\hline \multirow{2}{*}{$1 \mathrm{E}$} & Fscolha do problema & $\mathrm{P}$ & & & & & & & & & & & & & & & & & & & & \\
\hline & Escoma do pionienta & $\mathrm{R}$ & & & & & & & & & & & & & & & & & & & & \\
\hline \multirow{2}{*}{$2 \mid \mathrm{H}$} & Histórice do problema & $\mathrm{P}$ & & & & & & & & & & & & & & & & & & & & \\
\hline & & $\mathrm{R}$ & & & & & & & & & & & & & & & & & & & & \\
\hline \multirow[t]{2}{*}{$3 \mathrm{M}$} & Mostrar perdas atuais e qanhos viáveis & P & & & & & & & & & & & & & & & & & & & & \\
\hline & & $\mathrm{R}$ & & & & & & & & & & & & & & & & & & & & \\
\hline \multirow{2}{*}{$4 \mathrm{~F}$} & Fazer análise de Pareto & 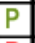 & & & & & & & & & & & & & & & & & & & & \\
\hline & & $\mathrm{R}$ & & & & & & & & & & & & & & & & & & & & \\
\hline 5 & Nomear resnonsáveis & $\mathrm{P}$ & & & & & & & & & & & & & & & & & & & & \\
\hline 5 & Nomear responsavels & $\mathrm{R}$ & & & & & & & & & & & & & & & & & & & & \\
\hline & Processo 2 - Observação & & & & & & & & & & & & & & & & & & & & & \\
\hline 10 & Coleta de dades & $\mathrm{P}$ & & & & & & & & & & & & & & & & & & & & \\
\hline 1 & Coleta de dados & $\mathrm{R}$ & & & & & & & & & & & & & & & & & & & & \\
\hline & Ohcenนar̃̃ nn local & $\mathrm{P}$ & & & & & & & & & & & & & & & & & & & & \\
\hline 2 & Observaçao no local & $\mathrm{R}$ & & & & & & & & & & & & & & & & & & & & \\
\hline & & $\mathrm{P}$ & & & & & & & & & & & & & & & & & & & & \\
\hline 3 & Cronograma, orçamento e meta & $\mathrm{R}$ & & & & & & & & & & & & & & & & & & & & \\
\hline & Processo 3 - Análise & & & & & & & & & & & & & & & & & & & & & \\
\hline 1 & Definicão das causas influentes & $\mathrm{P}$ & & & & & & & & & & & & & & & & & & & & \\
\hline & & $\mathrm{R}$ & & & & & & & & & & & & & & & & & & & & \\
\hline 2 & Escolha das causas mais prováveis & $\mathrm{P}$ & & & & & & & & & & & & & & & & & & & & \\
\hline & & $\mathrm{R}$ & & & & & & & & & & & & & & & & & & & & \\
\hline 3 & Análise das causas mais prováveis & $\mathrm{P}$ & & & & & & & & & & & & & & & & & & & & \\
\hline & & $\mathrm{R}$ & & & & & & & & & & & & & & & & & & & & \\
\hline & Processo 4 - Plano de ação & $\mathrm{P}$ & & & & & & & & & & & & & & & & & & & & \\
\hline & & $\mathrm{R}$ & & & & & & & & & & & & & & & & & & & & \\
\hline & Processo 5 - Execução & $\mathrm{P}$ & & & & & & & & & & & & & & & & & & & & \\
\hline & & $\mathrm{R}$ & & & & & & & & & & & & & & & & & & & & \\
\hline & Processo 6 - Verificação & & & & & & & & & & & & & & & & & & & & & \\
\hline 10 & Comnaracão dos resultados & $\mathrm{P}$ & & & & & & & & & & & & & & & & & & & & \\
\hline 1 & Comparaçao dos resultados & $\mathrm{R}$ & & & & & & & & & & & & & & & & & & & & \\
\hline 2 & Listagem dos efeitos secundários & $\mathrm{P}$ & & & & & & & & & & & & & & & & & & & & \\
\hline & & $\mathrm{R}$ & & & & & & & & & & & & & & & & & & & & \\
\hline 3 & Verificação continuidade ou não problema & $P$ & & & & & & & & & & & & & & & & & & & & \\
\hline & & $\mathrm{R}$ & & & & & & & & & & & & & & & & & & & & \\
\hline & Processo 7 - Padronização & & & & & & & & & & & & & & & & & & & & & \\
\hline 1 & Elaboração/alteração do padrão & $\mathrm{P}$ & & & & & & & & & & & & & & & & & & & & \\
\hline & & $\mathrm{R}$ & & & & & & & & & & & & & & & & & & & NA & \\
\hline 2 & Comunicação & $\mathrm{P}$ & & & & & & & & & & & & & & & & & & & & \\
\hline & & $\mathrm{R}$ & & & & & & & & & & & & & & & & & & & & NA \\
\hline 3 & Educacão e treinamento & $P$ & & & & & & & & & & & & & & & & & & & & \\
\hline & & $\mathrm{R}$ & & & & & & & & & & & & & & & & & & & & NA \\
\hline 4 & Acompanhamento da utilizacão do padrão & $\mathrm{P}$ & & & & & & & & & & & & & & & & & & & & \\
\hline 4 & Acompannamento da utulizaçao do paarao & $\mathrm{R}$ & & & & & & & & & & & & & & & & & & & & NA \\
\hline & Processo 8 - Conclusão & & & & & & & & & & & & & & & & & & & & & \\
\hline 10 & Relacão dos problemas & $\mathrm{P}$ & & & & & & & & & & & & & & & & & & & & \\
\hline 1 ] & Relaçao dos problemas & $\mathrm{R}$ & & & & & & & & & & & & & & & & & & & & \\
\hline 2 & Planejamento do ataque aos problemas & $\mathrm{P}$ & & & & & & & & & & & & & & & & & & & & \\
\hline & remanescentes & $\mathrm{R}$ & & & & & & & & & & & & & & & & & & & & NA \\
\hline 3 & Reflexão & $\mathrm{P}$ & & & & & & & & & & & & & & & & & & & & \\
\hline 3 & Renexao & $\mathrm{R}$ & & & & & & & & & & & & & & & & & & & & \\
\hline
\end{tabular}

